\title{
ИССЛЕДОВАНИЕ АКТИВНЫХ ОПЕРАЦИЙ КАК УГРОЗЫ ЭКОНОМИЧЕСКОЙ БЕЗОПАСНОСТИ КОММЕРЧЕСКОГО БАНКА
}

\author{
Е. И. Головань', С. А. Головань ${ }^{2}$, О. Ю. Оношко ${ }^{1}$ \\ ${ }^{1}$ Байкальский государственный университет, г. Иркутск, Российская Федерация \\ ${ }^{2}$ Иркутский государственный университет путей сообщения, г. Иркутск, Российская Федерация
}

\author{
Информация о статье \\ Дата поступления \\ 8 августа 2017 г. \\ Дата принятия к печати \\ 28 фревраля 2018 г. \\ Дата онлайн-размещения \\ 30 марта 2018 г.

\section{Ключевые слова} \\ Активные операции; \\ экономическая безопасность \\ банка; банковские риски; \\ методики расчета рисков
}

\begin{abstract}
Аннотация
В настоящее время наблюдается увеличение интереса к корпоративному управлению в коммерческих банках в целом и к управлению активами в частности. Это говорит о том, что корпоративное управление, направленное на минимизацию рисков, становится ведущим звеном в системе эффективного управления кредитной организацией. В статье рассматривается эволюция подходов к процессам управления рисками, анализируется понятие управления активами, описываются основные элементы кредитной политики с точки зрения управления кредитным риском активов, осуществляется его сравнение с рыночным риском. Большое внимание уделяется рыночному риску как совокупности частных рисков, приводятся методики их расчета и характеризуются проблемы их реализации. В статье делается вывод о роли оптимизации управления активами и рисков, присущих ему, в реализации угроз экономической безопасности коммерческого банка.
\end{abstract}

\section{ACTIVE TRANSACTIONS AS A THREAT TO THE ECONOMIC SECURITY OF A COMMERCIAL BANK}

\author{
Evgenii I. Golovan', Sophia A. Golovan², Olga Y. Onoshko' \\ ${ }^{1}$ Baikal State University, Irkutsk, the Russian Federation \\ ${ }^{2}$ Irkutsk State Transport University, Irkutsk, the Russian Federation
}

Article info

Received

August 8, 2017

Accepted

February 28, 2018

Available online

March 30, 2018

\section{Keywords}

Active transactions; economic security of the bank; banking risks; methodology for risk estimation

\begin{abstract}
There is an increasing interest in corporate management for commercial banks and in asset management in particular. This means that corporate management aimed at risk minimisation becomes a vanguard for the effective management system of credit companies. The evolution of methods for risk management processes is addressed, and the idea of asset management is being analyzed. The basic elements of the loan policy in the context of credit risk management and its comparison to the market risk are described. The article focuses on market risk as a set of private risks, the methodology for their estimation and implementation issues are defined. The article concludes the role of asset management optimization and its specific risks in materialization of the threats to the economic security of a commercial bank.
\end{abstract}

Увеличение интереса к корпоративному управлению в коммерческих банках в целом и управлению активами в частности неизменно происходит в период проявления кризисных явлений в экономике. В настоящее время вопросы об оптимальной структуре активов коммерческого банка, а также о соотношении отдельных элементов активов и пассивов между собой вновь становятся актуальными.

Исходя из исторических данных, можно заметить, что резкий всплеск интереса к различным аспектам корпоративного управления внутри коммерческого банка в зарубежной практике произошел в начале 1980-х гг., что было связано с изменением предлагаемого банками ассортимента продуктов. Это потребовало также разработки новых методов оценки риска и управления им, которые ранее были неизмеримыми.

Революционной для своего времени была разработка в 1988 г. Банком международных расчетов Базельского соглашения с целью 
обеспечения минимальных требований к капиталу для банков. К началу 1990-х гг. возник ряд дальнейших проблем в управлении рисками, и это привело к появлению в 1993 г. конкретной инициативы G30. В докладе «Деривативы: практика и принципы» были признаны и затронуты вопросы о производных продуктах и их использовании, а также сорормулированы рекомендации относительно надлежащего управления ими. Хотя отчет был посвящен исключительно деривативам, он охватывал ключевые аспекты практики управления рисками в целом - эти принципы стали признаваться лучшими'.

По мере осуществления Базельского соглашения было признано, что в рамках этого механизма существуют многочисленные недостатки, и в июне 2004 г. после проведения широких консультаций было опубликовано Базельское соглашение II. Эта версия заменила соглашение 1988 г. и была направлена на обеспечение того, чтобы распределение капитала было гораздо более чувствительным к рискам. Кроме того, он разделяет и количественно оценивает риски в компонентах кредитного, рыночного и операционного рисков, создавая жизнеспособную структуру и систему измерения для каждого из них². События, начавшиеся в 2007 г. в условиях кризиса, заставили регуляторы и фринансовые организации в глобальном масштабе вновь пересмотреть основы и процессы управления рисками, их анализ и ранжирование. Следствием этого стал выход Базеля III, утвержденного в 2010-2011 гг.

В течение последних десятилетий исследователи пытались описать, как банки решают вопрос о структуре активов и пассивов, чтобы оптимально соответствовать целям акционеров и менеджмента. Существуют различные мотивы для понимания этого процесса принятия решений. С точки зрения банков критически важно проанализировать структуру активов и пассивов в алгоритмическом процессе, несмотря на то что в конечном итоге применяемая стратегия является результатом обсуждений на уровне совета директоров [1].

С учетом того что управление активами заключается в выборе оптимальной структуры их распределения и исходя из сопоставления доходности и риска определяющее значение имеет грамотное управление активами, осуществляемое руководством банка. Таким образом, вопрос относительно распределения

${ }^{1}$ Risk Management and Asset and Liability Management in Banks // Risk Management Forum held at the Asian Development Bank Thailand Resident Mission in Bangkok on 26-28 November 2008. URL: https: / / www.quantinsti. $\mathrm{com} / \mathrm{blog} /$ risk-asset-liability-management-in-banks.

${ }^{2}$ lbid. активов по группам приносящих (в том числе внутреннее соотношение между чистыми вложениями в ценные бумаги и ссудную задолженность) и не приносящих доход активов позволяет судить о внутренней политике руководства банка и прогнозировать долгосрочность его финансовой устойчивости.

Исследованиями в данной области начиная с 50-60-х гг. занимались многочисленные ученые. Так, установление фракта, что банки, осуществляя инвестиционную деятельность, работают в балансирующем режиме риска-вознаграждения, описывается в новой для своего времени статье М. Марковица [2]. Постепенно в научной среде появляется мнение, что для описания управления как активами, так и пассивами необходимо применять методы математического и статистического программирования [3]. При этом одни исследователи применяли детерминированные математические модели [4], а другие - стохастические [5]. Обширный пласт научной литературы посвящен также исследованию роли непосредственно управления активами для прогнозирования банкротства банка и выбора оптимальной сбалансированной структуры активов и пассивов [6-9]. В данном контексте наибольший интерес с точки зрения управления структурой активов представляет первоначальное исследование кредитного и рыночного рисков коммерческого банка, присущих соответственно вложениям в ссудную задолженность и ценные бумаги.

Достаточно высокий в нашей стране «аппетит» банков к наращиванию кредитного портфеля, в том числе к кредитованию физических лиц без соответствующего обеспечения, способствует возрастанию и кредитного риска, требующего более тщательной оценки и управления. В портфеле банка потери обусловлены прямым невыполнением обязательств из-за неспособности или нежелания клиента (или контрагента) выполнять обязательства в отношении кредитования, расчетов и других финансовых операций. В качестве альтернативы потери могут быть результатом снижения стоимости портфеля вследствие фрактического или предполагаемого ухудшения качества кредита.

Самой первой целью кредитной стратегии банка является определение «аппетита» банка к риску. Как только это будет определено, банк может разработать план для оптимизации прибыли при сохранении кредитного риска в заранее определенных пределах. Таким образом, стратегия кредитного риска банка должна в обязательном порядке включать элементы, представленные на рис. 1. 


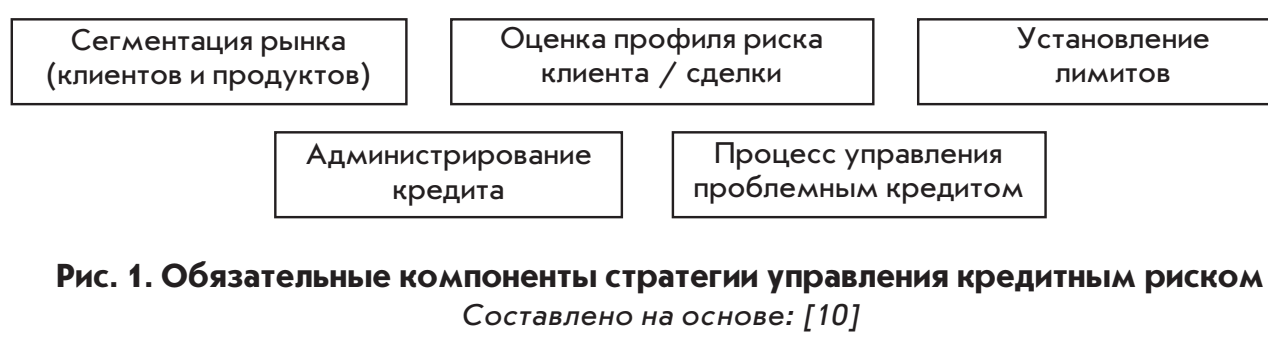

Так, для того чтобы назвать стратегию управления кредитным риском банка эффективной, необходимо, во-первых, чтобы кредитные процедуры были направлены на получение глубокого понимания качества клиентов банка с целью всеохватывающего представления о заемщиках банка. Необходимым элементом в аспекте сегментации также является фактор циклических изменений в экономике страны, позволяющий проводить политику непрерывно и отслеживать изменения в кредитном портфеле соразмерно происходящим сдвигам.

Во-вторых, должна проводиться адекватная оценка профиля риска конкретного клиента и сделки. Она должна включать среди прочего:

- кредитную оценку заемщика (оценку отрасли при кредитовании юридического лица);

- цель кредита и источник его погашения;

- кредитную историю заемщика;

- оценку возможностей погашения кредита заемщиком;

- адекватность залогов;

- макроэкономические факторы и др.

В-третьих, важным аспектом управления кредитным риском является установление лимитов на отдельные операции и заемщиков. Размер лимитов должен основываться на кредитоспособности должника, экономических условиях и допустимости риска конкретного банка. Положительным моментом для банка было бы установление ограничений для конкретной отрасли, экономического сектора или географических регионов, чтобы избежать риска концентрации.

В-четвертых, необходимо постоянное последующее администрирование кредитного портфеля, включающее в себя такие пункты, как:

- обеспеченность полноты документации;

- идентификация и контроль величины риска;

- своевременное выявление ухудшения кредитного портфеля и принятие мер по исправлению ситуации.

Заключительным, но одним из ключевых моментов управления кредитным риском банка являются принятые в банке процедуры по управлению проблемными кредитами.

Рекомендательными в данном аспекте выступают процедуры, направленные на усиление взаимодействия с проблемным заемщиком с целью решения возникшей ситуации. В некоторых случаях хороших результатов позволяет добиваться серия корректирующих мероприятий, таких как реструктуризация кредита [10, с. 15].

Как можно судить из вышеописанных элементов управления кредитным риском, процедура «сдерживания» риска в определенных границах представляется достаточно сложной и многоступенчатой. В то же время эфрфективность проводимой кредитной политики зависит по большей части от высшего менеджмента банка, и при адекватности проводимых мероприятий кредитный риск поддается управлению и минимизации. Соответственно, можно сказать, что структурные проблемы, связанные с кредитным риском активов, по большей части представляют собой ошибки именно руководства банка, вызванные чрезмерным стремлением к получению прибыли и расширением кредитного портфеля за счет заемщиков сомнительного качества. Причем данный пробел в государственном регулировании кредитного риска был отмечен на уровне Центрального банка, что привело к разработке и внедрению Положения о порядке расчета величины кредитного риска на основе внутренних рейтингов ${ }^{3}$, которое применяется вместе с указанием Банка России «О порядке получения разрешений на применение банковских методик управления кредитными рисками и моделей количественной оценки кредитных рисков в целях расчета нормативов достаточности капитала банка, а также порядке оценки их качества» ${ }^{4}$. Так, в Положении указано, что внедрение рейтинговых систем и оценка компонентов кредитного риска не должны быть направлены на исполь-

3 Положение о порядке расчета величины кредитного риска на основе внутренних рейтингов : утв. Банком России 6 авг. 2015 г. № 483-П (ред. от 1 дек. 2015 г.) / / СПС «КонсультантПлюс».

${ }^{4}$ О порядке получения разрешений на применение банковских методик управления кредитными рисками и моделей количественной оценки кредитных рисков в целях расчета нормативов достаточности капитала банка, а также порядке оценки их качества : указание Банка России от 6 авг. 2015 г. № 3752-У / / Там же. 
зование исключительно в целях расчета нормативов достаточности капитала. Внутренние рейтинги и оценки компонентов кредитного риска должны постоянно использоваться во внутренних процессах принятия решений и управления кредитным риском:

- при рассмотрении заявок о предоставлении финансирования и утверждении условий его предоставления;

- при определении лимитов кредитования;

- в рамках стратегического планирования капитала и его распределения;

- при подготовке внутренней отчетности;

- в целях контроля качества кредитного портфеля;

- для оценки результатов эфффективности деятельности банка, его бизнес-подразделений и доходности с учетом принимаемого риска;

- при определении размеров стимулирующих выплат (доплаты и надбавки стимулирующего характера, премии и иные поощрительные выплаты) для руководителей и отдельных категорий сотрудников, принимающих кредитные риски, размер которых связан с результатами принятия кредитных рисков, в том числе с возникшими фринансовыми потерями.

Таким образом, на сегодняшний момент Центральный банк устанавливает порядок оценки качества банковских методик управления кредитными рисками и моделей количественной оценки кредитных рисков для целей выдачи разрешения на применение внутренних рейтинговых методик. Этот порядок описывает процесс взаимодействия Банка России с банком, подавшим ходатайство на получение разрешения для применения внутренних рейтинговых методик, этапы и направления проведения оценки. Приведенный набор методов и инструментов, которые могут быть использованы Банком России в рамках валидации рейтинговых процессов и валидации моделей количественной оценки компонентов кредитного риска, в том числе указанные количественные тесты, не является исчерпывающим. В процессе валидации порядок действий сотрудников Банка России может быть скорректирован с учетом индивидуальных особенностей внутренних кредитных процессов и рейтинговых систем банка.

Совсем иным в вопросе управления представляется присущий в большей степени вложению в ценные бумаги рыночный риск. Рыночный риск представляет собой потенциальный убыток в результате неблагоприятного изменения фракторов рыночного риска, таких как процентные ставки, курсы валют, цены на акции и сырьевые товары. Таким образом, рыночный риск вложения в ценные бумаги можно представить как совокупность частных рисков (рис. 2).

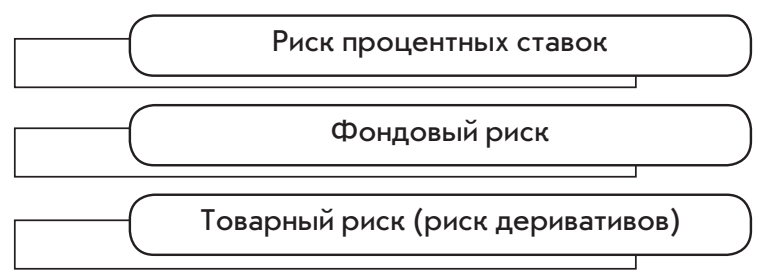

Рис. 2. Частные внутренние составляющие рыночного риска банка

Составлено на основе: [10] ; О порядке расчета кредитными организациями величины рыночного риска : положение Банка России от 3 дек. 2015 г. № 511-П

При выявлении процентного риска Базельский комитет рекомендует выделять четыре основные фрормы процентного риска, обусловленные источниками его возникновения:

- риск изменения стоимости позиций, связанный с несовпадением в сроках погашения (возврата) балансовых активов, пассивов и внебалансовых требований и обязательств с фиксированной процентной ставкой либо с установлением новой ставки по финансовым инструментам (с плавающей процентной ставкой);

- риск кривой доходности, связанный с возможным изменением угла наклона и фрормы кривой, отражающей равномерность получения дохода, вследствие несовпадения по времени погашения фринансовых инструментов при изменении процентных ставок по ним;

- базисный риск, обусловленный недостаточной корреляцией между процентными ставками по привлеченным и размещенным финансовым инструментам, имеющим сходный срок погашения и характеристики пересмотра процентной ставки;

- опционный риск, вызванный возможным отказом от исполнения обязательств одной из сторон сделки с автономными опционами либо финансовыми инструментами со встроенными опционами (например, депозиты с правом досрочного изъятия) [11].

Под фондовым риском в общем виде можно понимать риск, «возникающий не только при изменении справедливой стоимости инструментов фондового рынка, составляющих портфель ценных бумаг банка, но и при ухудшении финансового состояния эмитентов ценных бумаг, входящих в банковский портфель, и обусловленное этим фрормирование резервов на возможные потери по 
указанным инструментам, что может иметь для него крайне негативные последствия для банка» [12].

Фондовый риск возникает в следующих случаях:

- при отрицательной переоценке инструментов фрондового рынка, входящих в портфрель банка;

- при увеличении резервов на возможные потери по инструментам фондового рынка, входящим в портфель банка.

Под товарным риском в данном случае будем понимать риск, возникающий при использовании производных фринансовых инструментов, базисным (базовым) активом которых являются товары, договоров, по условиям которых соответствующие требования и (или) обязательства рассчитываются на основе цен на товары.

Для того чтобы оценить сложность корпоративного управления рыночным риском в коммерческом банке, обратимся к положению Банка России «О порядке расчета кредитными организациями величины рыночного риска» ${ }^{5}$. Так, процентный риск рассчитывается как сумма величин по формуле $П \mathrm{P}=\mathrm{CПР}+$ ОПР + ГВР(ПР), где ПР - процентный риск; СПР - специальный процентный риск, т. е. риск неблагоприятного изменения справедливой стоимости ценных бумаг и производных фринансовых инструментов под влиянием фракторов, связанных с эмитентом ценных бумаг, а также сроков, оставшихся до погашения ценных бумаг, и валюты, в которой номинированы и (или) фондированы ценные бумаги; ОПР - общий процентный риск, т. е. риск неблагоприятного изменения справедливой стоимости ценных бумаг и производных фринансовых инструментов, связанного с рыночными колебаниями процентных ставок; ГВР(ПР) - сумма гамма-риска и вега-риска по опционам, включаемым в расчет процентного риска.

При этом для расчета специального процентного риска все чистые позиции относятся к одной из групп с соответствующими коэффициентами риска (табл. 1). В то же время в положении дается очень подробное разъяснение относительно отнесения того или иного вида ценной бумаги к категории риска как относительно государственных ценных бумаг, так и эмитированных юридическими лицами.

${ }^{5} \mathrm{O}$ порядке расчета кредитными организациями величины рыночного риска : положение Банка России от 3 дек. 2015 г. № 511-П / / СПС «КонсультантПлюс».
Таблица 1

Коэффициенты для расчета специального процентного риска

\begin{tabular}{|c|c|}
\hline Величина риска & $\begin{array}{c}\text { Коэфрфициент } \\
\text { риска, \% }\end{array}$ \\
\hline Ценные бумаги без риска & 0 \\
\hline $\begin{array}{l}\text { Ценные бумаги с низким риском: } \\
\text { имеющим срок, оставшийся } \\
\text { до погашения, менее } 6 \text { месяцев }\end{array}$ & 0,25 \\
\hline $\begin{array}{l}\text { имеющим срок, оставшийся } \\
\text { до погашения, от } 6 \text { до } 24 \text { месяцев }\end{array}$ & 1 \\
\hline $\begin{array}{l}\text { имеющим срок, оставшийся } \\
\text { до погашения, свыше } 24 \text { месяцев }\end{array}$ & 1,6 \\
\hline $\begin{array}{l}\text { По ценным бумагам с низким } \\
\text { риском }\end{array}$ & 8 \\
\hline $\begin{array}{l}\text { По ценным бумагам с высоким } \\
\text { риском }\end{array}$ & 12 \\
\hline $\begin{array}{l}\text { По ценным бумагам, являющимся } \\
\text { инструментами секьюритизации: } \\
\text { с низким риском }\end{array}$ & 1,6 \\
\hline с риском ниже среднего & 4 \\
\hline со средним риском & 8 \\
\hline с риском выше среднего & 28 \\
\hline с высоким риском & 100 \\
\hline $\begin{array}{l}\text { По ценным бумагам, являющимся } \\
\text { инструментами повторной секью- } \\
\text { ритизации: } \\
\text { с низким риском }\end{array}$ & 3,2 \\
\hline с риском ниже среднего & 8 \\
\hline со средним риском & 18 \\
\hline с риском выше среднего & 52 \\
\hline с высоким риском & 100 \\
\hline \multicolumn{2}{|c|}{$\begin{array}{l}\text { Источник: О порядке расчета кредитными органи- } \\
\text { зациями величины рыночного риска : положение Банка } \\
\text { России от } 3 \text { дек. } 2015 \text { г. № } 511 \text {-П. }\end{array}$} \\
\hline
\end{tabular}

Относительно расчета фондового риска уровень риска определяется аналогичным образом, при этом чистые позиции по производным финансовым инструментам, базисным (базовым) активом которых является Индекс ММВБ 50, Индекс РТС 50 или индексы акций, включаются в расчет специального фондового риска с коэффициентом риска, равным 2 \%. Чистые позиции по производным фринансовым инструментам, базисным активом которых являются прочие индексы акций, включаются в расчет специального фондового риска с коэффрициентом риска, равным $8 \%$.

Таким образом, можно сделать вывод, что с точки зрения управления рыночным риском в банке менеджмент банка, принимая решение о вложении в те или иные ценные бумаги, уже имеет структурированную методику расчета величины совокупного риска по каждому вложению. Соответственно, управление рыночным риском банка в данном случае заключается в выборе оптималь- 
ной структуры распределения вложений исходя из соотношения доходности, ликвидности и риска с опорой на существующую методику. Сравнивая различия в управлении ссудной задолженностью и вложениями в ценные бумаги, необходимо заметить, что управление ссудной задолженностью в большей степени расположено в зоне ответственности непосредственно менеджмента банка, что, несмотря на большую свободу в выборе методик оценки заемщиков, увеличивает риски неверно принятых решений. Регулятор же в данном случае регламентирует конечный результат и предъявляет требования к достаточности капитала, уровню ликвидности, адекватности созданных резервов и т. д. Следовательно, можно предположить, что именно смещение структуры активов банка в сторону увеличения ссудной задолженности и уменьшение альтернативного вложения в ценные бумаги требует более грамотного управления со стороны менеджмента банка и представляет собой наибольшую угрозу экономической безопасности банка. Данный вывод согласуется с полученными ранее данными $[5 ; 8 ; 13]$.

Рассматривая вышеописанные документы, посвященные управлению рисками с целью противодействия кризисным явлениям в экономике в целом и в финансовом секторе в частности, можно сделать вывод, что в большинстве случаев разработанные рекомендации касаются одной важной составляющей - корпоративного управления активами и пассивами (asset-liability management). По мнению большинства исследователей, управление активами и пассивами определяет долгосрочную позицию для инвестирования активов и покрытия обязательств, будь то в один момент времени в будущем или в течение нескольких будущих периодов. Следовательно, можно сказать, что данное управление должно носить скорее стратегический характер на уровне коммерческого банка, нежели тактический [13].

Необходимо отметить, что, несмотря на то что именно активные операции коммерческого банка представляют собой угрозу его экономической безопасности, управление на уровне одной организации невозможно без комплексной оценки ее активов и пассивов. Представляя проблему иначе, можно сказать, что со стратегической точки зрения было бы неправильно фокусировать исследование лишь на активных операциях как таковых, но было бы правильно оценивать риски от размещения финансовых ресурсов во взаимосвязи с принятыми обязательства- ми, что подводит к необходимости рассматривать риск потери ликвидности как одну из основополагающих угроз экономической безопасности коммерческого банка.

Управление активами и пассивами включает в себя оптимальное инвестирование активов с учетом выполнения текущих задач по получению доходности и расчет по будущим обязательствам. Ключевой момент в управлении активами и пассивами банка - это совместная оценка рисков и выгод исходя из соотношения активов и обязательств. Управление активами и пассивами - это продолжающийся процесс разработки, внедрения, мониторинга и пересмотра стратегий для достижения финансовых целей организации с учетом допустимых рисков организации и других ограничений. Выгода грамотного управления активами и обязательствами для банка очевидна:

- понимание общей позиции компании в отношении ее обязательств;

- комплексное стратегическое управление и инвестиции с учетом обязательств;

- способность количественно оценивать риски и предпочтения риска;

- лучшая подготовка к будущей неопределенности;

- эфрорективность и результативность управления6.

Признавая эти преимущества, банки реализуют свою политику в области управления активами и пассивами. Во-первых, каждое учреждение имеет свои конкретные цели и принятые ограничения риска, которые определяют специфику распределения портфеля активов. Во-вторых, долгосрочные стратегические решения зависят от фракторов, прогнозы которых частично меняются при появлении новой информации. В-третьих, предпочтения в отношении рисков и их изменения с течением времени должны быть переведены на математический язык, который далеко не тривиален.

Недостаточное или несвоевременное управление активами и обязательствами приводит к возникновению риска ликвидности, который считается основным риском для банков. Он появляется тогда, когда имеющихся ликвидных активов недостаточно для выполнения своих обязательств. Однако условия финансирования через рынок зависят от ликвидности на рынке и ликвидности самого банка. Соответственно, учреждение, лишенное ликвидности, может вплотную приблизиться к банкротству, если не смо-

6 Risk Management and Asset and Liability Management in Banks. 
жет провести сделку даже по текущим рыночным ценам. Риск ликвидности не может рассматриваться изолированно, поскольку финансовый риск не является взаимоисключающим, и риск ликвидности возникает вследствие других фринансовых рисков, таких как кредитный риск, рыночный риск и т. д. По мнению некоторых ученых, в каждом банке можно рассматривать совокупность индикаторов, свидетельствующих о наличии проблем в области управления ликвидностью раньше, чем это будет проявляться при расчете коэффрициентов ликвидности [10, с. 27].

Примерами таких внутренних индикаторов являются:

- отрицательная тенденция к повышению концентрации принятого риска в отдельной области или линии;

- ухудшение качества кредитного портфеля;

- снижение показателей прибыли или прогнозов относительно прибыли;

- быстрый рост активов, финансируемый за счет изменчивого крупного депозита;

- ухудшение оценки третьей стороной (аудиторы, рейтинговые агентства и т. д.) о банке.

В рекомендациях Базельского комитета III от 2013 г. особое значение уделено нормативам коэфффициентов ликвидности банков ${ }^{7}$. Представленный в нем коэфффициент покрытия ликвидности призван гарантировать, что банки имеют достаточный запас высококачественных ликвидных активов (HQLA), которые могут быть легко немедленно конвертированы на частных рынках в денежные средства для удовлетворения их потребностей в ликвидности в течение 30 календарных дней. Мониторинг коэффрициента покрытия ликвидности призван улучшить способность банковского сектора выдерживать потрясения, вызванные финансовым и экономическим стрессом, независимо от источника, таким образом уменьшая риск распространения финансового кризиса на реальную экономику.

Во время ранней фразы финансового кризиса, которая началась в 2007 г., многие банки, несмотря на достаточный уровень капитала, по-прежнему испытывали трудности, поскольку не проявляли должной осторожности в отношении своей ликвидности. До кризиса рынки активов были гибкими, и фринансирование было легко доступно по низким ценам. Быстрый разворот в рыночных условиях показал, как быстро ликвидность может

${ }^{7}$ Basel III: The Liquidity Coverage Ratio and liquidity risk monitoring tools // Basel Committee on Banking Supervision, 2013. 75 p. URL: https://www.bis.org/ publ/bcbs238.htm. уменьшаться и что отсутствие ликвидности может длиться в течение длительного периода. Банковская система оказалась под сильным стрессом, что потребовало действий в поддержку функционирования как денежных рынков, так и отдельных институтов. Трудности, с которыми сталкиваются некоторые банки, объясняются упущениями в основных принципах управления риском ликвидности.

Так, предложенный коэффрициент расчета ликвидности состоит из двух компонентов: запас качественных высоколиквидных активов (HQLA) в стрессовых условиях; общий чистый отток денежных средств, рассчитанный на последующие 30 календарных дней ${ }^{8}$ :

Коэфффициент покрытия ликвидности =

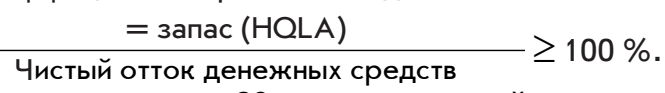
в течение следующих 30 календарных дней

При этом, для того чтобы обеспечить плавный переход к максимальному коэфффициенту расчета достаточности ликвидности, планируется постепенное увеличение норматива (табл. 2).

Таблица 2

Нормативы коэффициента

достаточности ликвидности в 2015-2019 гг., \%

\begin{tabular}{|l|l|l|l|l|}
\hline 1 января & 1 января & 1 января & 1 января & 1 января \\
\hline
\end{tabular}

\begin{tabular}{|c|c|c|c|c|}
\hline 2015 г. & 2016 г. & 2017 г. & 2018 r. & 2019 г. \\
\hline
\end{tabular}

\begin{tabular}{|l|r|r|r|r|}
60 & 70 & 80 & 90 & 100 \\
\hline
\end{tabular}

Источник: Basel III: The Liquidity Coverage Ratio and liquidity risk monitoring tools.

При этом в качестве высококачественных ликвидных активов признаются активы, перечисленные в табл. 39 .

Таблица 3

Виды активов и норматив для их включения

\begin{tabular}{|c|c|}
\hline Виды активов & $\begin{array}{c}\text { Норматив включения } \\
\text { в высококачественные } \\
\text { ликвидные активы }\end{array}$ \\
\hline $\begin{array}{l}\text { Активы уровня } 1: \text { монеты } \\
\text { и банковские билеты, го- } \\
\text { сударственные долговые } \\
\text { ценные бумаги, ценные } \\
\text { бумаги международных } \\
\text { банков развития, резервы } \\
\text { в Центральном банке }\end{array}$ & $100 \%$ \\
\hline
\end{tabular}
в высококачественные ликвидные активы

${ }^{8}$ Basel III: The Liquidity Coverage Ratio and liquidity risk monitoring tools.

9 Более подробно о методике отнесения ценных бумаг и расчете величины включения в высококачественные ликвидные активы см.: Basel III: The Liquidity Coverage Ratio and liquidity risk monitoring tools. 
Окончание табл. 3

\begin{tabular}{|c|c|}
\hline Виды активов & $\begin{array}{c}\text { Норматив включения } \\
\text { в высококачественные } \\
\text { ликвидные активы }\end{array}$ \\
\hline $\begin{array}{l}\text { Активы уровня 2: } \\
\text { уровень 2А: государ- } \\
\text { ственные долговые } \\
\text { ценные бумаги, ценные } \\
\text { бумаги международных } \\
\text { банков развития, призна- } \\
\text { ющиеся на уровне риска } \\
20 \text { \% в соответствии с } \\
\text { методикой Базель II, } \\
\text { корпоративные долго- } \\
\text { вые ценные бумаги с } \\
\text { рейтингом АА- и выше }\end{array}$ & Максимум 40 \% \\
\hline $\begin{array}{l}\text { уровень 2В: корпоратив- } \\
\text { ные долговые ценные } \\
\text { бумаги с рейтингом от } \\
\text { А+ до ВВВ-; жилищные } \\
\text { ипотечные ценные бумаги; } \\
\text { обыкновенные акции }\end{array}$ & Максимум 15 \% \\
\hline
\end{tabular}

Следовательно, проблему управления активами банка в качестве угрозы экономической безопасности можно определить как выбор не только оптимального соотношения между альтернативными вложениями в ссуды и ценные бумаги, но и общей оптимальной структуры с учетом высококачественных ликвидных активов для удовлетворения требований к коэффрициенту ликвидности.

Подводя итог проведенному исследованию, можно сделать вывод, что активные операции в коммерческом банке представляют угрозу экономической безопасности с учетом влияния сопряженных с ними рисков, в особенности кредитных и рыночных, а как следствие - риска утери ликвидности. Корпоративное управление активами представляет собой сложную многоступенчатую задачу, учитывающую как микро-, так и макроэкономические факторы. На основе анализа элементов кредитного риска нами был сделан вывод, что управление кредитным портфрелем банка во многом зависит непосредственно от менеджеров банка и их видения необходимости проводить рискованность политики. Действия регулятора в данном случае в течение длительного времени были направлены больше на контроль конечного результата (к примеру, достаточности капитала и др.), предоставляя большую свободу в выборе структуры вложений в ссуды по видам заемщиков, отраслям деятельности, разработке методик оценки заемщиков и т. д. В то же время такая ситуация приводила к обнаружению внутренних проблем слишком поздно, что не позволяло Центральному банку отслеживать рискованность кредитной политики на всех этапах. Это обусловило необходимость разработки ряда документов, предъявляющих требования непосредственно к внутренним методикам рейтинговой оценки риска. Аналогично можно судить и о вложении в ценные бумаги, в то же время учитывая тот фракт, что разработанная Банком России методика оценки рыночного риска более стандартизованная, а также факт необходимости соответствовать требованиям достаточности ликвидности, для расчета которой включаются определенные высококачественные ликвидные активы.

\section{СПИСОК ИСПОЛЬЗОВАННОЙ ЛИТЕРАТУРЫ}

1. Romanyuk Y. Asset-liability management: An overview / Y. Romanyuk // Bank of Canada Discussion Paper. - 2010. - № 10. - P. 1-37.

2. Markowitz H. M. Portfolio selection / H. M. Markowitz // The Journal of Finance. - 1952. - Vol. 7, № 1. - P. 77-91.

3. Kosmidou K. Goal Programming Techniques for Bank Asset Liability Management / K. Kosmidou, C. Zopounidis. - Boston : Springer, 2004. - 166 p.

4. Chambers D. Inter-temporal analysis and optimization of bank portfolios / D. Chambers, A. Charnes // Management Science. - 1961. - Vol. 7, iss. 4. - P. 393-410.

5. Kusy M. I. A bank asset and liability management model / M. I. Kusy, W. T. Ziemba // Operations Research. - 1986. - Vol. 34, iss. 3. - P. 356-376.

6. Adam A. Handbook of asset and liability management: from models to optimal return strategies / A. Adam. - New York : John Wiley \& Sons, 2007. - 576 p.

7. Agénor P. R. The credit crunch in East Asia: what can bank excess liquid assets tell us? / P. R. Agénor, J. Aizenman, A. W. Hoffmaister // Journal of International Money and Finance. - 2004. - Vol. 23, № 1. P. 27-49.

8. Halaj G. Optimal asset structure of a bank-bank reactions to stressful market conditions / G. Halaj // Working paper. - 2013. - № 1533.

9. Hałaj G. Risk-based Decisions on the Asset Structure of a Bank under Partial Economic Information / G. Hałaj / / Applied Mathematical Finance. - 2008. - Vol. 15, iss. 4. - P. 305-329.

10. Rose P. S. Risk Management Guidelines for Commercial Banks \& DFls. State of Pakistan bank «Commercial Bank Management» / P. S. Rose. - McGraw-Hill, 2002. - 39 p.

11. Бобыль В. В. Процентный риск банка: методы оценки и управление / В. В. Бобыль // Финансовая аналитика: проблемы и решения. - 2015. - № 11 (245). - С. 27-36. 
12. Егорова А. В. Факторы и условия формирования фондового риска в коммерческом банке / А. В. Егорова // Вестник Финансового университета. - 2012. - № 4. - С. 119-127.

13. Choudhry M. Bank asset and liability management: strategy, trading, analysis / M. Choudhry. New York : John Wiley \& Sons, 2011. - 1440 p.

\section{REFERENCES}

1. Romanyuk Y. Asset-liability management: An overview. Bank of Canada Discussion Paper, 2010, no. 10, pp. $1-37$.

2. Markowitz H. M. Portfolio selection. The Journal of Finance, 1952, vol. 7, no. 1, pp. 77-91.

3. Kosmidou K., Zopounidis C. Goal Programming Techniques for Bank Asset Liability Management. Boston, Springer, 2004. 166 p.

4. Chambers D., Charnes A. Inter-temporal analysis and optimization of bank portfolios. Management Science, 1961, vol. 7, iss. 4, pp. 393-410.

5. Kusy M. I., Ziemba W. T. A bank asset and liability management model. Operations Research, 1986, vol. 34 , iss. 3 , pp. $356-376$.

6. Adam A. Handbook of asset and liability management: from models to optimal return strategies. New York, John Wiley \& Sons, 2007. 576 p.

7. Agénor P. R., Aizenman J., Hoffmaister A. W. The credit crunch in East Asia: what can bank excess liquid assets tell us? Journal of International Money and Finance, 2004, vol. 23, no. 1, pp. 27-49.

8. Halaj G. Optimal asset structure of a bank - bank reactions to stressful market conditions. Working paper, 2013, no. 1533.

9. Hałaj G. Risk-based Decisions on the Asset Structure of a Bank under Partial Economic Information. Applied Mathematical Finance, 2008, vol. 15, iss. 4, pp. 305-329.

10. Rose P. S. Risk Management Guidelines for Commercial Banks \& DFls. State of Pakistan bank «Commercial Bank Management». McGraw-Hill, 2002. 39 p.

11. Bobyl V. V. Interest risk in the banking: evaluation methods and management. Finansovaya analitika: problemy i resheniya = Financial Analytics: Science and Experience, 2015, no. 11 (245), pp. 27-36. (In Russian).

12. Egorova A. V. Factors and terms for fund risk generation in commercial banks. Vestnik Finansovogo universiteta $=$ Bulletin of The Financial University, 2012, no. 4, pp. 119-127. (In Russian).

13. Choudhry M. Bank asset and liability management: strategy, trading, analysis. New York, John Wiley \& Sons, 2011. 1440 p.

\section{Информация об авторах}

Головань Евгений Игоревич - аспирант, кафредра банковского дела и ценных бумаг, Байкальский государственный университет, 664003, г. Иркутск, ул. Ленина, 11, e-mail: superdjen@mail.ru.

Головань Софья Андреевна - кандидат экономических наук, старший преподаватель, кафедра финансов и бухгалтерского учета, Иркутский государственный университет путей сообщения, 664074, г. Иркутск, ул. Чернышевского, 15, e-mail: free9sonjas@gmail.com.

Оношко Ольга Юрьевна - кандидат экономических наук, доцент, кафедра банковского дела и ценных бумаг, Байкальский государственный университет, 664003, г. Иркутск, ул. Ленина, 11, e-mail: olga_onoshko@mail.ru.

\section{Для цитирования}

Головань Е. И. Исследование активных операций как угрозы экономической безопасности коммерческого банка / Е.И.Головань, С. А. Головань, О. Ю. Оношко // Известия Байкальского государственного университета. - 2018. - Т. 28, № 1. - C. $105-113$. - DOI: $10.17150 / 2500-$ 2759.2018.28(1).105-113.

\section{Authors}

Evgenii I. Golovan - postgraduate student, Department of Banking and Securities, Baikal State University, 11 Lenin St., 664003, Irkutsk, the Russian Federation, e-mail: superdjen@mail.ru.

Sophia A. Golovan - PhD in Economics, Senior Lecturer, Department of Finance and Accounting, Irkutsk State Transport University, 15 Chernyshevsky St., 664074, Irkutsk, the Russian Federation, e-mail: free9sonjas@gmail.com.

Olga Y. Onoshko - PhD in Economics, Associate Professor, Department of Banking and Securities, Baikal State University, 11 Lenin St., 664003, Irkutsk, the Russian Federation, e-mail: olga_onoshko@mail.ru.

\section{For citation}

Golovan E. I., Golovan S. A., Onoshko O. Y. Active Operations as a Threat to the Economic Security of a Commercial Bank. Izvestiya Baykal'skogo gosudarstvennogo universiteta $=$ Bulletin of Baikal State University, 2018, vol. 28, no. 1, pp. 105-113. DOI: 10.17150/2500-2759.2018.28(1).105-113. (In Russian). 